February 2002

\title{
The issue of instability in a simple policy game between the central bank and a representative union*
}

\author{
Giovanni Di Bartolomeo $^{\mathrm{ab}}$ and Wilfried Pauwels ${ }^{\mathrm{a}}$ \\ (a) Faculty of Applied Economics UFSIA-RUCA, University of Antwerp \\ (b) Public Economics Department, University of Rome 'La Sapienza'
}

\begin{abstract}
In the recent economic literature the independence of the central bank is often considered to be one of the most effective guarantees to achieve price stability. A strong theoretical basis of this proposition is that the monetary policy delegation given to an independent central bank is an optimal instrument to avoid the time inconsistency problem of monetary policy. This paper investigates the stability properties of this solution in a simple game in which the private sector (i.e. the trade unions) and the public sector (i.e. the central bank) simultaneously interact. A representative monopoly union is considered, and-in line with the recent economic debate-two types of unions are investigated: i) the standard micro-founded trade union; ii) the inflation-averse trade union. In both cases, we find that the requirement that the Nash equilibrium be stable imposes a limit to the conservativeness of the central bank. Instability of the Nash equilibrium reveals a strategic co-ordination failure between the public and the private sector.
\end{abstract}

JEL codes: $\quad$ E52, E55, E61, J51, C62, C70.

Keywords: Central bank independence, inflation bias, inflation spiral, stability.

\footnotetext{
* We are grateful to N. Acocella, G. Ciccarone, P. Flaschel, F. Lippi and E. Marchetti for very appreciated comments and suggestions on previous drafts. Giovanni Di Bartolomeo gratefully acknowledges the financial support from 'Progetto Giovani Ricercatori' of the Italian MURST and from BOF (Special Research Fund) of the University of Antwerp. Corresponding author address: Giovanni Di Bartolomeo, Faculty of Applied Economics UFSIA-RUCA, University of Antwerp, Prinsstraat 13, 2000 Antwerp, Belgium. Telephone: +32 (0)3 220 4132, Fax: +32 (0)3 220 4799, e.mail: giovanni.dibartolomeo@ufsia.ac.be.
} 


\section{Introduction}

In an important paper, Rogoff (1985) has suggested to solve the inflationary bias, caused by the lack of consistency of monetary policy, by delegating monetary policy to an independent and conservative central bank, i.e., an independent monetary authority that cares less about unemployment than the government does. This difference in preferences reduces the expected rate of inflation, and hence also the actual rate of inflation.

The standard monetary policy model supports this view. This is so because a more inflation-averse central bank will be less tempted to trade-off higher inflation for (only short-term) gains in output and employment. Lower unemployment is a worthwhile policy target in the standard model because rigidities, such as those created by trade union's market power, lead to an equilibrium employment that is too low. In other words, Rogoff (1985) proposes a solution to the time inconsistency problem, first identified by Kydland and Prescott (1977) in their seminal contribution. Other solutions to this problem have been suggested. ${ }^{1}$ However, in this paper we focus only on the straightforward solution proposed by Rogoff (1985), for two reasons. First, this solution, as we will show, it is no longer straightforward when the issue of the stability of the Nash equilibrium is raised. Secondly, the conservative central banker is the most popular proposal suggested by economists regarding institutional remedies against inflation. ${ }^{2}$

On the theoretical side, ${ }^{3}$ several recent papers have questioned the theoretical foundation of the conservative central banker solution by allowing for direct interaction of non-atomistic agents and monetary policy. This literature tries to endogenise the inflation bias by considering non-atomistic trade unions that set the nominal wages, taking into account the reaction of the central bank to the implied real wage (Cubitt, 1992, 1995 and 1997; Gylfason and Lindbeck, 1994, Acocella and Ciccarone, 1997; Cukierman and Lippi, 1999 and 2000; Guzzo and Velasco, 1999; and Berger et al. 2001).

The crucial assumption of these models is that unions are generally assumed to be inflation-averse agents, i.e. that their target functions include not only some real wage and employment target but also the costs of inflation. The effects of this assumption are remarkable. Unions who dislike inflation moderate their wage claims in order to reduce the central bank's incentives for an inflationary policy. This has one important consequences for the traditional monetary policy model. The behaviour of inflationaverse trade unions establishes a direct link between the central bank's preferences and real labour market outcomes (i.e. monetary policy is non-neutral ${ }^{4}$ ). Such a link does not exist in the standard framework. A more conservative central bank will prefer tolerating a higher unemployment rate to an increased inflation. A trade union,

\footnotetext{
${ }^{1}$ See, e.g., Possen (1985), Lohmann (1992) and Walsh (1995).

2 Rogoff's analysis has been extended and refined in many papers The most important of them is Svensson (1997). For other extensions, see the survey of Piga (2000). Our paper can be useful to better understand some of these other contributions. It is impossible for us to consider all the alternative analyses.

${ }^{3}$ Empirical research on the conservative central banker controversy has not given a definitive answer to the question of the central bank's independence. Cf. De Haan and van't Hag (1995), Bleneay (1996), Forder (1998), Eijffinger et al. (1998), Walsh (1998: Ch. 8), Possen (1998) and Piga (2000).

${ }^{4}$ Generally, this kind of non neutrality is also defined as strategic non neutrality to avoid confusion with the traditional non neutrality of monetary policy which is defined for exogenous changes in the monetary aggregate or interest rate (see Lippi, 1999).
} 
which is inflation averse, will be more moderate since the larger nominal wage increases raise inflation, and will therefore lead to an intervention by the central bank's. This will imply higher unemployment. On the other hand, a conservative central bank will raise unemployment, and, therefore, make the wage-money race more expensive for both the private and the public sector.

This paper focuses on Rogoff's proposition about the conservative central banker in a unionised labour market with a representative trade union. In its simplest definition, Rogoff's proposition claims that the higher the central bank's weight attached to inflation, the lower the inflation is. This proposition holds in general. However, as mentioned above, Rogoff's claim is not a free-lunch proposition when inflationaverse unions are assumed. Therefore, in this paper, in order to consider both cases (a union which is, or is not, inflation averse $)^{5}$, we define the Rogoff proposition in a strong and a weak version.

1. The strong version of Rogoff's proposition states that increases in the degree of conservativeness (i.e. the weight attached to inflation by the central bank) always reduce the inflation rate, without cost in terms of output. This is the original Rogoff proposition.

2. The weak version states that increases in the degree of conservativeness always reduce the inflation rate. However, the higher the degree of conservativeness, the higher is unemployment. This is Rogoff's proposition when inflation-averse unions are assumed.

In both cases, we investigate the stability properties of the Nash equilibria of the games that underlie these propositions. All the games considered will be simple static games, widely used in the literature. . The issue of the stability property of a Nash equilibrium is often studied in industrial organisation games (e.g. Seade, 1980; and Henriques, 1990). In policy-games, however, the stability issue has always been ignored.

As the stability issue for this type of games is not completely clear in the literature (see Seade, 1980; Henriques, 1990; Milgrom and Roberts 1990; and Mas-Colell et al, 1995: 248-50), we have explicitly modelled two different possible types of dynamic adjustment processes. One involves dynamic adjustments by only one player. The other adjustment involves simultaneous moves by both players. Both processes are consistent with the assumptions about information, generally adopted in the policygames of the kind studied here, i.e. the so-called Nash conjectures. We do not consider more complex dynamic adjustments involving intertemporal utilities, discount rates and more sophisticated conjectures. However, despite its limitations, our exercise can be considered as a limiting case where agents sufficiently discount the future, and form myopic (Nash) conjectures about the actions of their rivals. The relaxations of these assumptions is important, but it is outside the scope of this paper.

The paper is organised as follow. The next section defines the general set-up used in the paper. Section 3 outlines Rogoff's proposition, where wage-setters are explicitly considered. The section solves the model as a static policy game played by the central bank and an inflation-neutral union. This section also analyses the equilibrium stability conditions. We focus mainly on the effects and on the interpretation of the

\footnotetext{
${ }^{5}$ However, it must be clear that here we do not consider the assumption of unions' inflation-aversion on its own merit. For this, see, e.g., Gylfason and Lindbeck, (1994). We are only interested in studying the effects of this assumption. See, e.g., Iversen and Soskice (2000).
} 
stability condition. A more formal analysis of the dynamic adjustment processes is given in the appendix. Section 4 generalises the previous analysis to an inflationaverse union. Section 5 summarises our findings, and draws some conclusions.

\section{The general set-up}

The economy is described by a Barro-Gordon (1983) type model, which generalise the model used by Gylfason and Lindbeck (1994), Cubitt (1997) and Acocella and Ciccarone (1997) by considering a basic set-up where the elasticity of the aggregate demand with respect to the real money balances and that of the aggregate supply with respect to the real wage are not necessarily equal to one.

The following relationship gives the aggregate demand for output

$$
Y_{t}^{D}=V_{t}\left(\frac{M_{t}}{P_{t}}\right)^{\rho}
$$

where $Y_{t}^{D}$ is the aggregate demand at time $t, M_{t}$ is the nominal money supply, $P_{t}$ is the price level, $\rho$ is the real money balance elasticity of aggregate demand, and $V_{t}$ is a demand stochastic shock with unitarian expected values and realisations, which are independent and identically distributed, i.e. $\ln \left(V_{t}\right) \sim$ iid $\left(0, \sigma_{V}{ }^{2}\right)$. Equation [1], by making aggregate demand for output dependent upon real money balances, shows the traditional inverse relationship, for a given money supply, between the demand for output and the price level. Equation [1] is very general and can be obtained in several ways. E.g., when it is assumed that $\rho=1$, equation [1] is the quantity theory of money. ${ }^{6}$

The aggregate production function is Cobb-Douglas, with labour as the only variable input :

$$
Y_{t}^{S}=A_{t} N_{t}^{a} \bar{K}_{t}^{1-a} \quad a \in(0,1)
$$

where $Y_{t}^{S}, N_{t}$ and $\bar{K}_{t}$ are output, employment and the given capital stock at time $t$, respectively. $A_{t}$ is a stochastic total productivity factor (supply shock) with $\ln \left(A_{t}\right) \sim$ iid $\left(0, \sigma_{A}^{2}\right)$.

Assuming that firms maximise profits, given the nominal wage and the price level, the aggregate labour demand is given by:

$$
\frac{W_{t}}{P_{t}}=a A_{t}\left(\frac{\bar{K}_{t}}{N_{t}}\right)^{1-a}
$$

where $W_{t}$ is the nominal wage rate.

The goods market clearing condition is:

$Y_{t}^{D}=Y_{t}^{S}$

By equation [4], we can, henceforth, refer to both $Y_{t}^{D}$ and $Y_{t}^{S}$ as $Y_{t}$ (i.e. the output).

\footnotetext{
${ }^{6}$ An equation of the kind of equation [1] can be also derived by solving the maximisation problem of the households in a monopolistic competition model (see, e.g., Blanchard and Kiyotaki, 1985).
} 
Taking then the logs of equation [1]-[3], the log-linear version of our economy can be summarised by the following three equations:

$y_{t}=\rho\left(m_{t}-p_{t}\right)+v_{t}$

$y_{t}=a n_{t}+\varepsilon_{t}$

$w_{t}-p_{t}=-\frac{1}{\eta} n_{t}+\varepsilon_{t}$

$\eta=\frac{1}{1-a}$ is the real wage elasticity of the labour demand. $v_{t}=\ln \left(V_{t}\right)$ and $\varepsilon_{t}=\ln \left(A_{t}\right)$

are the two stochastic shocks previously defined. Furthermore, as usual, $\bar{K}_{t}$ is assumed equal to one and the labour demand shift parameter is omitted without loss of generality. ${ }^{7}$ Equation [5] is the log-aggregate demand for output, equation [6] is the log-aggregate supply of output, and equation [7] is the log-aggregate labour demand.

The reduced form for output, employment and price of model [5]-[7] is given by

$y_{t}=\frac{b \rho}{b+\rho}\left(m_{t}-w_{t}\right)+\kappa_{t}$

$n_{t}=\frac{\eta \rho}{b+\rho}\left(m_{t}-w_{t}\right)+\eta v_{t}$

$p_{t}=\frac{\rho}{b+\rho} m_{t}+\frac{b}{b+\rho} w_{t}+v_{t}$

$b$ is defined as $b=\frac{a}{1-a} . \quad \kappa_{t}=\left(\frac{b v_{t}+\rho \varepsilon_{t}}{b+\rho}\right)$ and $v_{t}=\left(\frac{v_{t}-\varepsilon_{t}}{b+\rho}\right)$ are two linear combinations of the stochastic terms $\varepsilon_{t}$ and $v_{t}$ previously defined. As we will see, the implications of these shocks will depend on the stability or instability of the prevailing equilibrium.

\section{Rogoff's proposition in a union-central bank policy-game framework}

There are two policy-making agents in the economy: the trade union, and the central bank. The union sets the nominal wage and the central bank sets the nominal money supply. Both players take as given the constraints implied by the economic model described in the previous section. ${ }^{8}$

The union's loss function is quadratic in the employment and linear in the real wage: ${ }^{9}$

\footnotetext{
${ }^{7}$ Results are available upon request.

${ }^{8}$ This implies that no explicit expression for rational expectations compare in the model, since the nominal wage are set simultaneously to the money supply. This way to solve the model is widely used (e.g. Gylfason and Lindbeck, 1994; Cubitt, 1995 and 1997; and Acocella and Ciccarone, 1997). It gives a result that is equivalent to that of the models that explicitly consider the expectations (see appendix A). However, discriminating among the two ways of solving the game is outside the scope of the paper, as the above economists, we consider only the first one.

${ }^{9}$ Loss functions of this type are common in the policy games. See, among others, Gylfason and Lindbeck (1994), Acocella and Ciccarone (1997) and Cukierman and Lippi (1999 and 2000). However, we have checked the robustness of our results with respect to other general specifications of the union
} 


$$
L_{U}=E_{t}\left[\frac{a^{2}}{2}\left(n_{t}-n_{U}\right)^{2}-\alpha\left(w_{t}-p_{t}\right)\right]
$$

The operator $E$ is the expectation in $t$ at $t-1$, and $n_{U}$ is the desired employment level.

The central bank's loss function is a quadratic function in inflation and output. ${ }^{10}$

$$
L_{B}=\frac{1}{2} E_{t}\left[\left(y-y_{B}\right)^{2}+\beta\left(\pi-\pi_{B}\right)^{2}\right]
$$

$\beta$ is the degree of conservativeness of the central bank. Inflation $\pi_{t}$ is defined by $\pi_{t}=p_{t}-p_{t-1} \cdot \pi_{B}=p_{B}-p_{t-1}$ and $y_{B}$ are the central bank's target-values of inflation and output, respectively.

As usual in the literature, the central bank is assumed to have a higher employment target than that desired by the private sector (i.e. the trade union): $y_{U}=a n_{U} \leq a n_{B}=y_{B}$.

In order to simplify the exposition, and without loss of generality, we assume that $p_{B}=p_{t-1}$, so that $\pi_{B}=0$. We consider a game in which the union sets the nominal wage, and in which the central bank sets the money supply. These two decisions are taken simultaneously. The equilibrium concept is that of a Nash equilibrium. This framework has become very common in recent years. ${ }^{11}$ Furthermore, it must be noted that our analysis is consistent with the model of Kydland and Prescott. ${ }^{12}$ However, this last class of models is not our primary study objective since our focus is on the recent policy-games involving unions.

In order to obtain the Nash equilibrium, we first derive the reaction functions. These functions are obtained by solving the following two problems. The union's problem is:

$$
\min _{w_{t}} L_{U}=E_{t}\left[\frac{a^{2}}{2}\left(n_{t}-n_{U}\right)^{2}-\alpha\left(w_{t}-p_{t}\right)\right]
$$

subject to equations [9] and [10]. The central bank's problem is:

$$
\min _{m_{t}} L_{B}=E_{t}\left[\frac{1}{2}\left(y_{t}-y_{B}\right)^{2}+\beta\left(\pi_{t}-\pi_{B}\right)^{2}\right]
$$

subject to equations [8] and [10].

The resulting reaction functions are then

$$
w_{t}=m_{t}-n_{U}+\frac{\alpha}{a b}
$$

\footnotetext{
preference function (i.e. quadratic in both arguments and linear in the output and quadratic in the real wage). See Acocella and Di Bartolomeo (2001b) for a detailed discussion of the specification of union's preferences in this kind of games.

${ }^{10}$ This loss function is very common in the policy games. See Walsh (1998: 325-327) for a full discussion of it.

${ }^{11}$ See, e.g., Gylfason and Lindbeck (1994), Acocella and Ciccarone (1997), Guzzo and Velasco (1999).

12 See, e.g., Stokey (1990), Sargent (1999), or Deissenberg and Gonzales (2001).
} 
$m_{t}=\frac{b(b \rho-\beta)}{\left(b^{2}+\beta\right) \rho} w_{t}+\frac{b(\rho+b)}{\left(b^{2}+\beta\right) \rho} y_{B}+\frac{(\rho+b) \beta}{\left(b^{2}+\beta\right) \rho} p_{t-1}$

Since the optimisation problems are both minimisation of linear-quadratic loss functions, subject to linear constraints with additive shocks, the reader should note that the certainty equivalence theorem holds, so that in our context solving the stochastic or the non-stochastic problem is the same.

Solving [15] and [16] for $w$ and $m$ gives the Nash equilibrium values $w_{N}$ and $m_{N}$. Using these values in [8] and [10], we obtain the Nash equilibrium values of output and inflation:

$y_{N}=a n_{U}-\frac{\alpha}{b}+\kappa_{t}$

$\pi_{N}=\frac{\alpha}{\beta}+\frac{b}{\beta}\left(y_{B}-\alpha n_{U}\right)+v_{t}$

In this model the standard result of monetary policy neutrality holds: the equilibrium level of output is independent of the central bank's degree of conservativeness. At the same time, the equilibrium level of inflation is decreasing in the degree of conservativeness. This is the strong Rogoff proposition.

We now study the stability of this Nash equilibrium. For this purpose, we consider the following familiar adjustment process. The trade union takes the value of $m$, as determined by the government, as given. It then uses its reaction function [15] to determine its corresponding best value of $w$. The central bank then takes this value of $\mathrm{W}$ as given, and uses its reaction function [16] to determine its corresponding best value of $m$. This adjustment process is continued indefinitely. The question is then whether this adjustment process converges to the Nash equilibrium. It is well-known that this will depend on the relative slopes of the two reaction functions.

Consider then figure 1 . The dotted lines describe the central bank's optimal targets. The upward sloping dotted line is the locus in $(w, m)$-space where $y=y_{B}$. The downward sloping dotted line is the locus where $\pi=\pi_{B}$. Therefore, point A is the central bank's optimal point, i.e., the point where the central bank achieves the minimum loss possible. Figure 1 also gives the players' reaction functions. As the slope of the trade union's reaction function is equal to one, the trade union will always react to an increase (decrease) of $m$ by increasing (decreasing) the wage level w. Using the terminology of industrial organisation, $w$ and $m$ are always strategic complements for the trade union. If, e.g., the central bank would increase $m$, the trade union will react by deciding to increase $w$ to the same extent. The result of this reaction is that output and the real wage do not change.

On the other hand, the size and the sign of the slope of the central bank's reaction function depends on the values of $b, \theta$ and $\beta$. The degree of conservativeness $\beta$ measures the rate of substitution between the deviations of output and inflation from the central bank's targets. Suppose that the central bank is faced with an increase in $w$, relative to the value of $w$ at point $\mathrm{N}$, the Nash equilibrium. To the extent that this will decrease output and employment, the central bank will increase $m$. However, to the extent that the increase of $w$ raises inflation, the central bank will decrease $m$. If then the central bank's concern for inflation is sufficiently small, the first effect will 
dominate, and the slope of the central bank's reaction function will be positive. If, on the other hand, the central bank cares very strongly about inflation, the second effect will dominate, and the slope of the central bank's reaction function will be negative. Therefore, increasing the value of $\beta$ will rotate the central bank's reaction function clockwise around point $A$ on figure 1. If $\beta=0$ the reaction function coincides with the $y=y_{B}$ locus, while when $\beta=\infty$ the reaction function coincides with the $\pi=\pi_{B}$ locus.

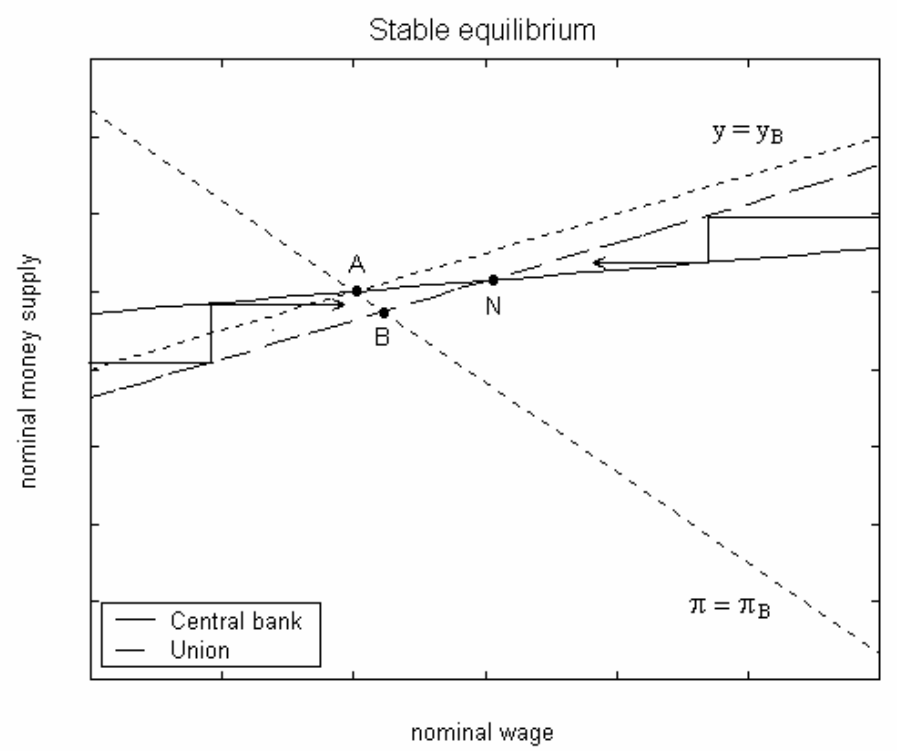

Fig. 1

On figure 1 we assumed $\beta$ to be relatively small, so that the slope of the central bank's reaction function is positive. This is the case when $b \rho>\beta$. $w$ and $m$ are then strategic complements for the central bank. It is easy to see graphically that in this case the values of $w$ and $m$ converge monotonically to their Nash equilibrium values, given by the point $\mathrm{N}$. In this case, the Nash equilibrium will be stable.

On figures 2 and 3 we assume that the slope of the central bank's reaction function is negative, i.e. that $b \rho<\beta$. For the central bank $w$ and $m$ are then strategic substitutes. If now the central bank is faced with an increase in the wage level (relative to the wage level at point $\mathrm{N}$ ), it will decrease $m$ in order to control the inflationary pressures of the wage level increase. This policy reduces output and employment. In order to increase output, the union will decrease wages. The central bank will increase the money supply in order to decrease the deflation. The union will then reply by increasing $w$. And so it goes on. On figure 2 this process converges in an oscillatory pattern to the Nash equilibrium. In case of figure 3 this oscillatory process does not converge. 


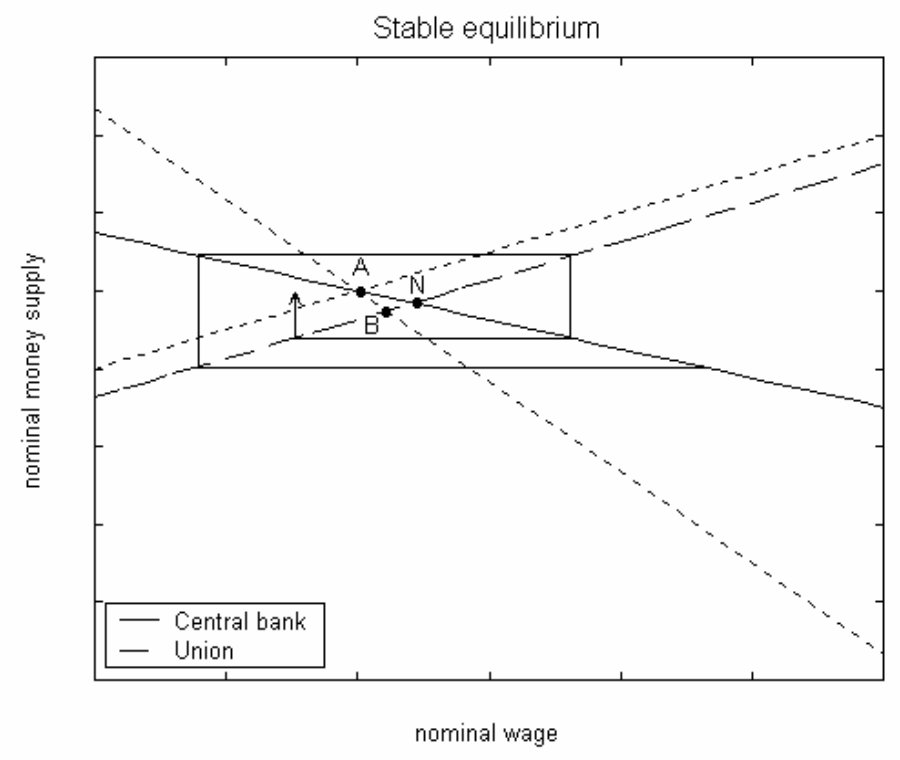

Fig. 2

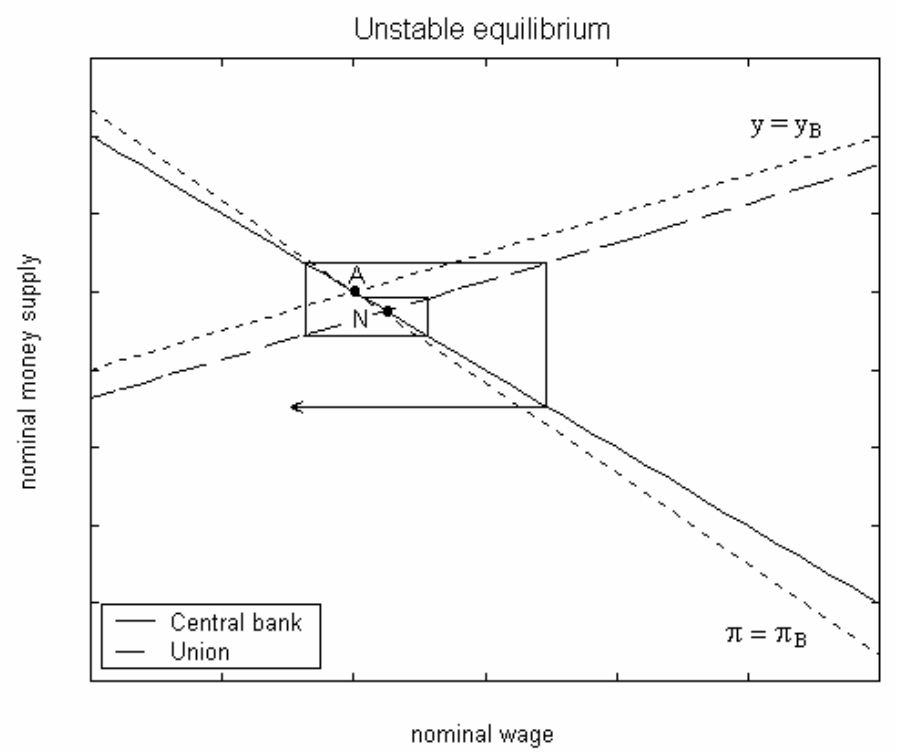

Fig. 3

In the appendix it is shown that the stability condition is given by the following inequality, involving the slopes of the agents' reaction functions:

$\left|\frac{b(b \rho-\beta)}{\left(b^{2}+\beta\right) \rho}\right|<1 \Leftrightarrow|b \rho-\beta|<\frac{\left(b^{2}+\beta\right) \rho}{b}$

According to the sign of $(b \rho-\beta)$, we distinguish two cases. When $\beta<b \rho$ it straightforward to see that the stability condition is always satisfied. When $\beta>b \rho$ the stability condition becomes:

$(b-\rho) \beta-2 b^{2} \rho<0$ 
This is satisfied for all $\beta \leq \beta_{U L}$, where

$$
\beta_{U L}=\frac{2 b^{2} \rho}{b-\rho}
$$

When $\rho \leq b$ the Nash equilibrium is always stable since the upper limit of conservativeness is not economically significant $\left(\beta_{U L}<0\right)$. When $b>\rho$, the equilibrium can be unstable since $\beta_{U L}$ is then always positive. Therefore, for $b>$ $\rho$, the strong Rogoff proposition is meaningful only if the conservativeness of the central bank is-limited.

The argument is summarised in figure 4. The slope of the central bank's reaction function varies between two extreme values: 1 which is the slope of the locus $y=y_{B}$, and $-\frac{b}{\rho}$ which is the slope of the locus $\pi=\pi_{B}$.

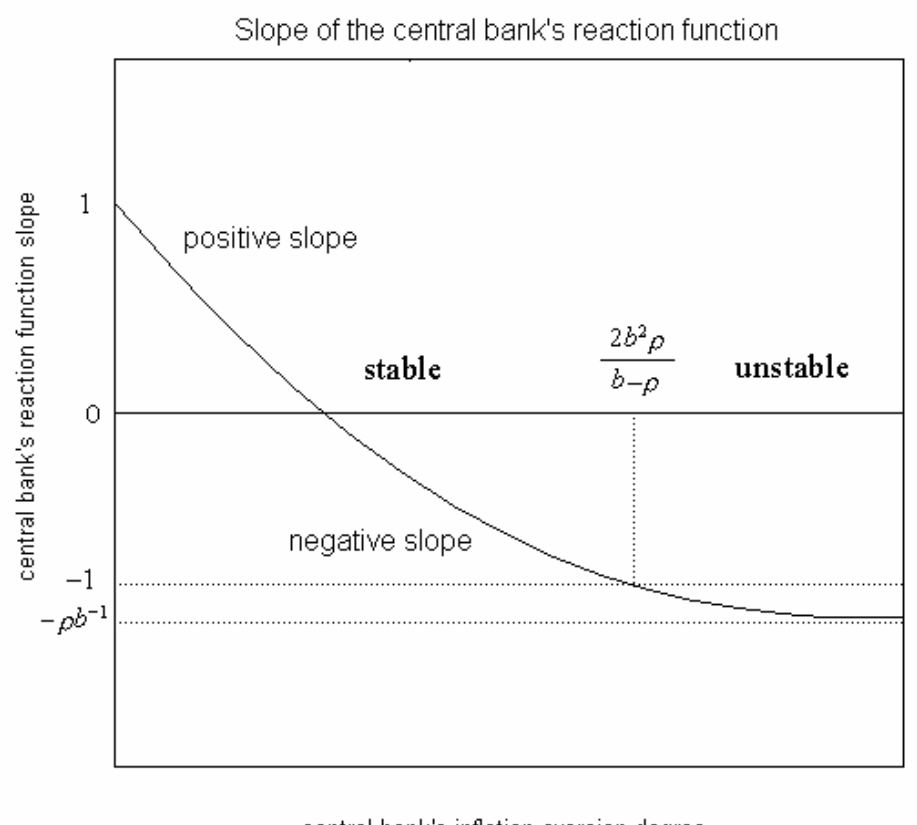

Fig. 4

Instability clearly requires two conditions. First, we must have that $\rho<b$. By equation [10] this means that $p$ is more affected by $w$ than by $m$. Secondly, we require $\beta>\beta_{U L}$. This means that the central bank has to be sufficiently conservative

Uncoordinated policies can, therefore, generate divergent cyclical movements. The instability can emerge when inflation depends more on $w$ than on $m$. In economic terms, this instability is the result of a strategic co-ordination failure ${ }^{13}$ between the public sector (i.e. the central bank) and the private sector (i.e. the union) in setting

\footnotetext{
13 Note that strategic co-ordination failure is not the same as traditional co-ordination failure described by Cooper and Jhn (1988), unless it is assumed that the unstable solution is Pareto dominated by the stable one.
} 
their instruments. Both agents follow their optimal strategies, but these strategies are not compatible with a stable equilibrium. This result supports the idea that, in this kind of game, the co-operative solution represents a superior institutional arrangement. However, cooperation is often not feasible (see Acocella and Di Bartolomeo (2001a).

\section{A generalization: an inflation-averse trade union}

Let us now generalise the union's loss function [11] by assuming that it is quadratic in inflation and output and linear in the real wage:

$$
L_{U}^{*}=E_{t}\left[\frac{a^{2}}{2}\left(n-n_{U}\right)^{2}-\alpha(w-p)+\frac{\vartheta}{2}\left(\pi-\pi_{U}\right)^{2}\right]
$$

$\vartheta$ measures the union's inflation-aversion. $\pi_{U}=p_{U}-p_{t-1}$ is the union's inflation target. For a more accurate description of such functions we refer to Gylfason and Lindbeck (1994), Acocella and Ciccarone (1997) and Cukierman and Lippi (1999 and 2000). In order to simplify the exposition, and without loss of generality, we assume that $\pi_{U}=p_{U}=0$.

When solving problem [13] we now have to use [22] instead of [11]. The union's reaction function is now:

$$
w_{t}=\frac{b \rho^{2}-\vartheta \rho}{b \rho^{2}+b \vartheta} m_{t}-\frac{\rho^{2}+b \rho}{b \rho^{2}+b \vartheta}\left(a n_{U}-\frac{\alpha}{b}\right)+\frac{\rho+b}{b \rho^{2}+b \vartheta} \vartheta p_{t-1}
$$

The Nash equilibrium levels of output and inflation turn out to be:

$$
\begin{aligned}
& y_{N}^{*}=\frac{a \beta n_{U}+b \vartheta y_{B}}{\beta+b \vartheta}-\frac{\alpha \beta}{b(\beta+b \vartheta)}+\kappa_{t} \\
& \pi_{N}^{*}=\frac{\alpha \rho}{\beta+b \vartheta}+\frac{b}{\beta+b \vartheta}\left[\rho y_{B}-a(\rho+\vartheta) n_{U}\right]+v_{t}
\end{aligned}
$$

In line with the recent debate about the strategic monetary policy neutrality, it follows from [24] that monetary policy is not neutral when an inflation-averse union is assumed. This is the weak version of Rogoff's proposition. We now turn to the stability of this Nash equilibrium.

The stability condition is now given by the following inequality:

$$
\left|\left[\frac{b(b \rho-\beta)}{\left(b^{2}+\beta\right) \rho}\right]\left[\frac{(b \rho-\vartheta) \rho}{b\left(\rho^{2}+\vartheta\right)}\right]^{-1}\right|<1
$$

According to the sign of $|b \rho-\beta||b \rho-\vartheta|$, two cases are possible.

The first case arises when $\vartheta>b \rho$ and $\beta>b \rho$ or when $\vartheta<b \rho$ and $\beta<b \rho$. In this case the slopes of the reaction functions have the same sign. It is then easy to check that the stability condition always holds, and that $m$ and $w$ converge monotonically to their Nash equilibrium values. 
The second case arises when $\vartheta>b \rho>\beta$ or $\beta>b \rho>\vartheta$. The slopes of the reaction functions have opposite signs. The stability condition can then be rewritten in terms of $\beta$ as:

$$
[(b-\rho) \rho-2 \vartheta] \beta+(b-\rho)-2 b \rho^{2}<0
$$

When $\rho \geq b$, inequality [27] is always satisfied. However, when $b>\rho$, stability is not guaranteed. Hence, the weak Rogoff proposition is meaningful only if the central bank is not too conservative.

The conservativeness' upper limit is given by the following expression:

$$
\beta_{U L}{ }^{\prime}=\frac{2 b^{2} \rho^{2}-b(b-\rho) \vartheta}{(b-\rho) \rho-2 \vartheta}=\beta_{U L}+\frac{b(b+\rho)^{2} \vartheta}{(b-\rho) \rho-2 \vartheta}
$$

It follows that, when the union is inflation-averse, the upper limit to the conservativeness of the central bank is less stringent. In fact, from equation [28] is evident that if $\rho \geq b$ holds then $\beta_{U L^{\prime}}<0$, whereas if $\mathrm{b}>\rho$ holds then $\beta_{U L^{\prime}}>\beta_{U L}$.

In economic terms the instability is again driven by the reasons exposed in the previous section. However, when an inflation-averse union is considered, the effects of the wage on price are reduced by the perception of the union's association of the additional cost in terms of inflation which, in this case, is a direct argument of the union's preference function. Therefore, it is more difficult to observe a divergent cycle.

When the union cares about inflation, its reaction function must still go through point $\mathrm{B}$ on figures 1 and 2 , but it is no longer parallel to the locus $y=y_{B} .{ }^{14}$ The relationship between the union's degree of inflation-aversion and the slope of its the reaction function is given in figure 5 .

When $\theta$ increases, the union's reaction function rotates anti-clockwise, and the Nash equilibrium gets closer to the zero inflation locus. This occurs because, when a union takes inflation into account, increases in the nominal wage give rise to a real cost (i.e. the higher inflation).

The mechanism becomes clearer by investigating two limiting cases for the slope of the union's reaction function. First, the union's reaction function exhibits a slope equal to 1 when $\vartheta$ equals zero. Therefore, the slope is equal to that of the locus $y=y_{B}$. In this case the union does not care about inflation. Its objectives are the output and the real wage. As each level of output corresponds to a unique real wage, this case is equivalent to the one in which it is assumed that the union only cares about the output (or real wage). Therefore, monetary policy is neutral in the sense that the central bank cannot affect the real level of output since each deviation from the optimal level for the union will be penalised by higher inflation rate (which are costs only for the central bank since the union does not care about inflation).

The other limit value for the slope of the union's reaction function, $-b / \rho$, occurs when $\vartheta$ tends to infinity. In this case, the slope of the union is equal to the slope of the locus $\pi=\pi_{B}$. The union, in fact, then cares only about inflation. Its preference function can be rewritten in terms of inflation only. Therefore, we observe a similar

\footnotetext{
${ }^{14}$ See Acocella and Di Bartolomeo (2001b) for the implications of this property on the monetary policy neutrality.
} 
case of that above described. Monetary policy cannot affect the inflation rate. However, since, in our case, there is no opposition of interest in terms of desired (optimal) inflation between the central bank and the union, the central bank's desired (optimal) level of real output can be achieved. ${ }^{15}$

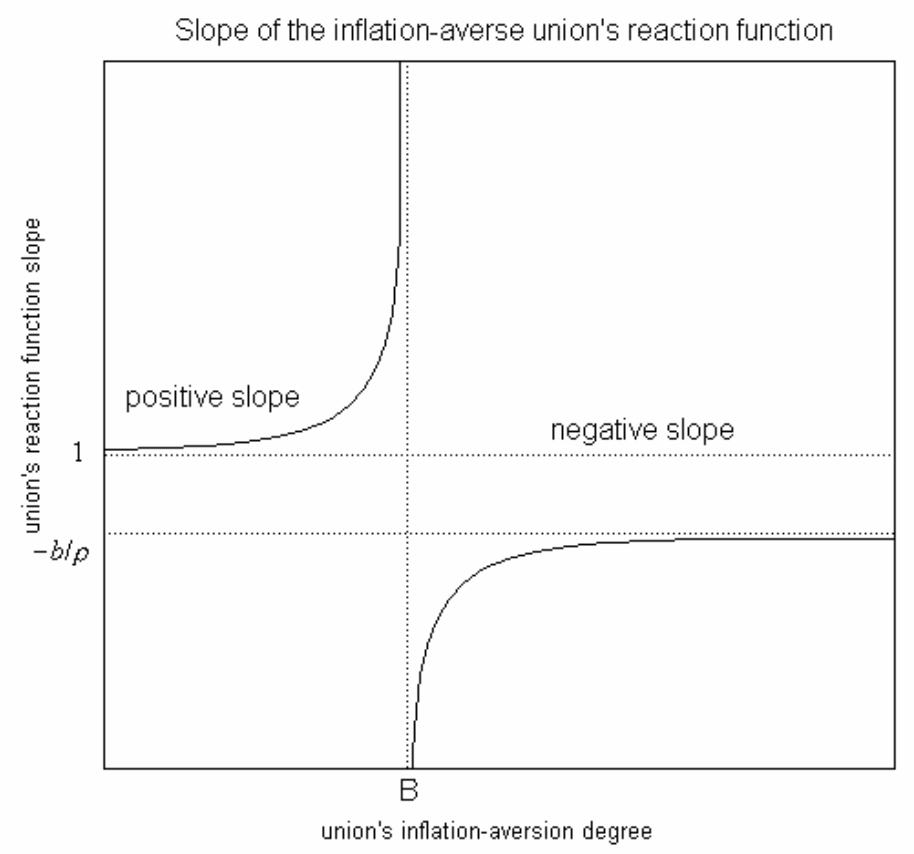

Fig. 5

The above results can be summarised as follows. According to figure 5, the slope of the union's reaction function (as a function of $\vartheta$ ) varies between 1 and $+\infty$, and between $-\infty$ and $-b / \rho$. The value of 1 is the slope of the locus $y=y_{B}$, and $-b / \rho$ is the slope of the locus $\pi=\pi_{B}$. From the previous section, we know that the slope of the central bank's reaction function (as a function of $\beta$ ) varies from one to $-b / \rho$. Using these two properties, we can now state two general propositions.

First, assume that the central bank's reaction function has a positive slope, i.e., the central bank cares relatively more about the employment target. If then $w$ and $m$ are strategic complements for the union, the Nash equilibrium is always stable. If $w$ and $m$ are strategic substitutes for the trade union, the Nash equilibrium can be unstable.

Second, assume that the central bank's reaction function has a negative slope, i.e., the central bank cares relatively more about inflation target. If then $w$ and $m$ are strategic complements for the union, the Nash equilibrium can be unstable. If $w$ and $m$ are strategic substitutes for the union, the Nash equilibrium cannot be unstable.

\footnotetext{
15 This particular result is derived from the assumption of equal desired inflation targets of the central bank and the union. If different inflation targets are assumed, this result does not hold, and we can observe a situation more similar to that described for the first case where the optimal evel of real output for the union differs from its desired value and, therefore, from that of the central bank. The union aims to achieve an output equilibrium value lower than its desired one because of the presence of gains from the higher real wage in its preference function (see Acocella and Di Bartolomeo, 2001b).
} 
Therefore, unstable solutions can emerge only if $m$ and $w$ are strategic complements for one agent and strategic substitutes for the other one. This means that unstable solutions always are of the oscillatory type, and that they derive from a co-ordination failure. This kind of failure is not a standard private or public co-ordination failure, but it is a strategic co-ordination failure between the private and the public sector.

\section{Conclusions}

In the present economic literature, the independence of the central bank is regarded as one of the most effective guarantees to achieve the price stability. A strong theoretical basis of this proposition is that monetary policy delegation given to an independent central bank is an optimal instrument to avoid the intertemporal inconsistency problem of announced anti-inflation policies. In this paper we have investigated the stability properties of this solution when the private sector, represented by a trade union, acts simultaneously with the public sector, represented by the central bank. According to the recent economic debate, both the case of an inflation-neutral union, and the case of an inflation-averse union, were considered. We found that in both cases a limit exists to the conservativeness of the central banker. The exact limit depends on the parameters determining the economic structure.

The limit emerges when the labour coefficient of the production function is high with respect to the elasticity of the demand with respect to the money real balances. In this case variations in the agents' controls (that are nominal variables) have very asymmetric effects on the price level. This can lead to instability. This limit implies a co-ordination failure problem between the public sector (i.e. the central bank) and the private sector (i.e. the union). In fact, uncoordinated policies can generate divergent cyclical solutions in which each agent, responding to the other agent's policy, follows a behaviour that leads the system away from the Nash equilibrium.

Our result seems to enforce the traditional idea of the superiority of the co-operative solution. In the literature on policy games involving unions, our analysis adds a further benefit to the co-operative solution since it can be used as co-ordination mechanism. However, this kind of superiority needs to be further investigated as new problems may arise when considering the cooperative solution. .

Considering an inflation-averse union, the effects of wage on price could be reduced when the additional cost in terms of inflation is higher than the additional benefit in terms of real wage. Therefore, the condition (in terms of central bank's conservativeness) to observe a divergent cycle (i.e. an unstable solution) becomes less stringent.

Simple observations show that instability is more than a theoretical possibility. A necessary condition for instability is that $\rho b^{-1}>1 .{ }^{16}$ We can then make two observations. First, theoretical models generally assume or derive $\rho=1$ (e.g. quantitative theory of money). Secondly, recall that $b$ represents the share of the labor over the capital in the production process. Empirical evidence tends to conclude that the value of this share is around 0.6 and 0.8 depending on the country, the sample, and the estimation technique selected. In this case the condition $\rho b^{-1}>1$ is clearly met. Of course, the evaluation of its relevance remains an empirical matter, which seems technically difficult to solve. However, the consideration of the possibility of

\footnotetext{
${ }^{16}$ It also becomes necessary when the union does nor care about inflation.
} 
instability cannot be a priori omitted in the theoretical modeling considered in our context.

Finally, we must underline the limits of our investigation. The most important limitation is that we do not consider more complex dynamic adjustment schemes, where inter-temporal utilities, discount rates and more sophisticated conjectures play a major rule. Also, several trade unions can be introduced. Despite the above limitations, ${ }^{17}$ our exercise certainly underlines that more attention has to given to the instability issue.

\footnotetext{
${ }^{17}$ However, our model can be considered as a limiting case where agents sufficiently discount the future and form myopic (Nash) conjectures about the actions of their rivals.
} 


\section{Appendix A - Rogoff's proposition in a standard rational expectations framework}

In the traditional model, the trade union is assumed to set the nominal wage before the central bank sets the nominal supply of money. In order to solve this model, we first have to derive the union's expectation about the future price level. The union's loss function is quadratic in employment, and linear in the real wage:

$$
L_{U}=E_{t-1}\left[\frac{a^{2}}{2}\left(n_{t}-n_{U}\right)^{2}-\alpha\left(w_{t}-p_{t}\right)\right]
$$

The operator $E_{t-1}$ is the expectation in $t$ at $t-1$ and $n_{U}$ is the desired employment level.

By minimising equation [A.1] under constraint [7], we obtain the expected optimal level of employment of the unions:

$$
\bar{n}=n_{U}-\frac{\alpha}{\eta}
$$

We can then derive the union's desired nominal wage from equation [7]:

$$
w_{t}^{*}=E_{t-1} p_{t}-\frac{\bar{n}}{\eta}
$$

Making simple algebraic substitutions, equations [6], [7] and [A.3] give the Lucas' type aggregate supply:

$$
y_{t}-\bar{y}=b\left[\pi_{t}-E_{t-1} \pi_{t}\right]+(1+b) \varepsilon_{t}
$$

where $\bar{y}=\alpha \bar{n}, b=\frac{a}{1-a}$ and $\pi_{t}=p_{t}-p_{t-1}$.

The central bank's problem is to minimise with respect to $m$ a quadratic function in inflation and output.

$$
\min _{m_{t}} L_{B}=\frac{1}{2} E_{t}\left[\left(y-y_{B}\right)^{2}+\beta\left(\pi-\pi_{B}\right)^{2}\right]
$$

\section{s.t. equation $[$ A.4]}

The central bank's minimisation problem under a rational expectations model constraint is solved by standard techniques (e.g. Minford, 1992: Chapter 2). The time consistent solution is given by the following expressions.

$$
\begin{aligned}
& y_{t}=\bar{y}+\kappa_{t}=y_{U}-\frac{\alpha}{b}+\kappa_{t} \\
& \pi_{t}=\frac{b}{\beta}\left(y_{B}-\bar{y}\right)+v_{t}=\frac{\alpha}{\beta}+\frac{b}{\beta}\left(y_{B}-\alpha n_{U}\right)+v_{t}
\end{aligned}
$$

Equations [A.6] and [A.7] imply the standard results of monetary policy neutrality and inflation bias. This bias is decreasing in the degree of conservativeness. In other words, the strong Rogoff's proposition holds. 


\section{Appendix B - Stability conditions}

\section{B.1 Cobweb best response adjustment}

The dynamics of the adjustment process can be described by the simple following cobweb model.

$$
\begin{aligned}
& w_{s}^{U}=m_{s}+n_{U}-\frac{\alpha}{a b} \\
& m_{s}^{B}=\frac{\rho b^{2}-b \beta}{\rho\left(b^{2}+\beta\right)} w_{s-1}+\frac{b(\rho+b)}{\rho\left(b^{2}+\beta\right)} y_{B}
\end{aligned}
$$

$m_{s}^{U}=m_{S}^{B}$

$w_{s}^{U}$ and $m_{s}^{B}$ are the optimal values of the nominal wage and money supply for the union and for the central bank, respectively; $s$ is defined in the interval $[t-1, t)$ and $s_{0}$ is equal to $t-1$. The interval does not include $t$, because the adjustment takes place before that the shocks are observed. ${ }^{18}$

The dynamic system [B.1] describes an adjustment process driven by the changes in the nominal wage. The assumption is that the trade union reacts with a lag to changes in the money supply. The central bank's reaction to changes in the money supply is instantaneous. An equivalent system can be written by considering the change in the nominal money supply as the driving variable.

The adjustment process [B.1] can be easily reduced to the following difference equation:

$$
w_{s}-\frac{\rho b^{2}-b \beta}{\left(b^{2}+\beta\right) \rho} w_{s-1}=\frac{b(b+\rho)}{\left(b^{2}+\beta\right) \rho} y_{B}+n_{U}-\frac{\alpha}{a b}
$$

The solution of the homogeneous part of equation [B.2] is:

$$
w_{s}=C\left(\frac{\rho b^{2}-b \beta}{\left(b^{2}+\beta\right) \rho}\right)^{s}
$$

where $C$ is a constant. A particular solution of equation [B.3] is:

$$
w=\frac{b}{\beta} y_{B}-\left(\frac{\beta+\eta^{2}}{b \beta}\right)\left(a n_{U}-\frac{\alpha}{b}\right)
$$

We then obtain

$$
m=\frac{b}{\beta} y_{B}-\left(\frac{b-\beta}{\beta}\right)\left(a n_{U}-\frac{\alpha}{b}\right)
$$

Plugging equations [B.4] and [B.5] in the reduced form of the model, we found the Nash equilibrium values for output and inflation described in the paper.

According to equation [B.3], the above Nash equilibrium is stable if and only if

\footnotetext{
${ }^{18}$ We have set $p_{t-1}=0$ assume to simplify the exposition. Results still remain valid since it affects only the initial position, without effect on the adjustments.
} 
$\left|\frac{b(\rho b-\beta)}{\left(b^{2}+\beta\right) \rho}\right|<1$

\section{B.2 Simultaneous best response adjustment}

More generally, we can define the adjustment process as a system of two difference equations. In this case the two agents really act simultaneously, taken the strategy of the other agent as given (Nash conjectures). ${ }^{19}$

Re-writing the two reaction-functions as:

$m=\phi w+\Phi$

$m=\psi w+\Psi$

we can derive the best response of the central bank, given the nominal wage, as:

$\Delta m=\lambda_{B}[\phi w+\Phi-m]$

where denotes $\Delta m$ the variation of $m$ and $\lambda_{B}$ describes the adjustment speed to the optimal value (i.e. when $\lambda_{B}=1$, the central bank's monetary policy coincides with its best response for a given nominal wage).

In a similar way, we obtain for the union Then we compute the same for the union obtaining:

$\Delta w=\lambda_{U}\left[\frac{1}{\psi} m-\frac{\Psi}{\psi}-w\right]$

where $\Delta w$ and $\lambda_{U}$ have the same meaning as the corresponding symbols above.

The dynamics of the adjustment process is the described by the following dynamic system:

$\left[\begin{array}{c}\Delta m \\ \Delta w\end{array}\right]=\left[\begin{array}{cc}\lambda_{B} & 0 \\ 0 & \lambda_{U}\end{array}\right]\left[\begin{array}{cc}-1 & \phi \\ \frac{1}{\psi} & -1\end{array}\right]\left[\begin{array}{l}m \\ w\end{array}\right]+\left[\begin{array}{c}\Phi \\ -\frac{\Psi}{\psi}\end{array}\right]$

A necessary and sufficient condition for the stability of the system [B.11] is

$\left|\left(1-\lambda_{B}\right)\left(1-\lambda_{U}\right)-\frac{\phi}{\psi}\right|<1$

Assuming that agents are able to implement their better response policy without lags (i.e. $\lambda_{B}=\lambda_{U}=1$ ), condition [B.12] becomes:

$\left|-\frac{\phi}{\psi}\right|<1 \Rightarrow|\phi|<|\psi|$

This condition is used in the paper.

\footnotetext{
${ }^{19}$ This adjustment process mainly derives from the Cournot's (1838) myopic adjustment procedure. However, see Milgrom and Roberts (1990) and Mas-Colell et al (1995: 248-50) for a full discussion on this point.
} 


\section{References}

Acocella, N. and G. Ciccarone (1997), “Trade unions, mnneutrality and stagflation”, Public Choice, 91: 161-178.

Acocella, N. and G. Di Bartolomeo (2001a), "Feasibility and robustness of the corporatism", Public Economics Department, University of Rome 'La Sapienza', Working Paper No. 44.

Acocella, N. and G. Di Bartolomeo (2001b), "Trade unions and nonneutrality: generalisation and extensions", University of Rome 'La Sapienza', mimeo.

Barro, R.J. and D.B. Gordon (1983), "A positive theory of monetary policy in a natural rate model", Journal of Political Economy, 81: 589-610.

Berger, H., C. Hefeker and R. Schöb (2001), "Optimal central bank conservatism and monopoly trade unions", CESIfo Working Paper No. 407.

Blanchard, O.J. and N. Kiyotaki (1987), "Monopolistic competition and the effects of aggregate demand", American Economic Review, 77: 647-666.

Bleneay, M. (1996), "Central bank independence, wage-bargaining structure, and macroeconomic performance in OECD countries", Oxford Economic Papers, 48: 2038.

Cournout, A. (1838), Recherches sur les principles mathématiques de la théorie des richesses translated in English with the title Researchers into the mathematical principles of the theory of wealth, New York, Macmillian, 1897.

Cubitt, R.P. (1992), "Monetary policy games and private sector precommitment", Oxford Economic Papers, 44: 513-530.

Cubitt, R.P. (1995), "Corporatism, monetary policy and macroeconomic performance: a simple game theoretic analysis", Scandinavian Journal of Economics, 97(2): 245259.

Cubitt, R.P. (1997), "Stagflationary bias and the interaction of monetary policy and wages in a unionized economy", Public Choice, 93: 165-178.

Cukierman, A. and F. Lippi (1999), "Central bank interdependence, centralization of wage bargaining, inflation and unemployment - Theory and evidence", European Economic Review, 43: 1395-1434.

Cukierman, A. and F. Lippi (2000), "Labour markets and monetary union: a strategic analysis", Banca d'Italia, Servizio Studi, Temi di discussione No. 365.

Cuper, R. and A. John (1988), "Coordination coordination failure in keynesian models", Quarterly Journal of Economics, 83: 441-463.

De Haan, J. and G.J. van't Hag (1995), "Variation in central bank independence across countries: some provisional empirical evidence", Public Choice, 85: 335-371.

Deissenberg, C. and F.A. Gonzales (2001), "Cheating for the common good in a macroeconomic policy game", Department of Economics, Université de la Méditerranée (Aix-Marseille II), mimeo.

Eijffinger, S.C.W., E. Schaling and M. Hoeberichts (1998) "Central bank independence: a sensitivity analysis", European Journal of Political Economy, 14: 7388 . 
Forder, J. (1998), "The case for an independent European Central Bank: a reassessment of evidence and sources", European Journal of Political Economy, 14: 53-71.

Guzzo, V. and A. Velasco (1999), "The case for a populist central banker", European Economic Review, 43: 1317-1344.

Gylfason, G. and A. Lindbeck (1994), "The interaction of monetary policy and wages", Public Choice, 79: 33-46.

Henriques, I. (1990), "Cooperative and non cooperative R\&D in duopoly with spillovers: Comment", American Economic Review, 80: 638-640.

Iversen, T. and D. Soskice (2000), "The non neutrality of monetary policy with large price or wage setters", Quarterly Journal of Economics, 115: 265-284.

Kydland, F.W. and E.C. Prescott (1977), "Rules rather than discretion: the inconsistency of the optimal plans", Journal of Political Economy, 85: 473-491.

Lippi, F. (1999), "Strategic monetary policy with non-atomistic wage setters: a case for non-neutrality”, CEPR Discussion Paper No. 2218.

Lohmann, S. (1992), "Optimal commitment in monetary policy: credibility versus flexibility", American Economic Review, 82: 273-86.

Mas-Colell, A., W. Whinston and J.R. Green (1995), Microeconomic theory, Oxford, Oxford University Press.

Milgrom, P. and J. Robersts (1990), "Rationalizability, learning and equilibrium in games with strategic complementarities", Econometrica, 58: 1255-1278.

Minford, P. (1992), Rational expectations macroeconomics, Oxford, Blackwell.

Piga, G. (2000), "Dependent and accountable: evidence from the modern theory of the central banking", Journal of Economic Surveys, 14: 563-595.

Posen, A.S. (1995), "Declarations are not enough: financial sector sources of central bank independence", NBER Macroeconomic Annual: 253-274.

Posen, A.S. (1998), "Central bank independence and disinflationary credibility: a missing link", Oxford Economic Papers, 50: 235-259.

Rogoff, K. (1985), "The optimal degree of commitment to an intermediate monetary target”, Quarterly Journal of Economics, 100: 1169-1190.

Sargent, T.J. (1999), The conquest of American inflation, Princeton, Princeton University Press.

Seade, J. (1980), “The stability of Cournot revised", Journal of Economic Theory, 23: $15-27$.

Stokey, N.L. (1990), "Reputation and time inconsistency", American Economic Review, 79: 134-139.

Svensson, L.E.O. (1997), "Optimal inflation target 'conservative' central banks and linear inflation contracts”, American Economic Review, 87: 98-114.

Walsh, C.E. (1995), "Optimal contracts for central bankers", American Economic Review, 85: 150-167.

Walsh, C.E. (1998), Monetary theory and policy, Cambridge (MA), MIT Press. 